\title{
Implications and management of anemia in cardiac surgery: Current state of knowledge
}

\author{
Gabriel Loor, MD, ${ }^{a}$ Colleen G. Koch, MD, MS, MBA, ${ }^{\mathrm{b}}$ Joseph F. Sabik III, MD, ${ }^{\mathrm{a}}$ Liang Li, PhD, ${ }^{\mathrm{c}}$ and \\ Eugene H. Blackstone, $\mathrm{MD}^{\mathrm{a}, \mathrm{c}}$
}

Decreasing oxygen delivery during and after cardiopulmonary bypass (CPB) can adversely affect patient outcomes. Balancing morbidities associated with anemia, red blood cell (RBC) transfusion, pharmaceuticals to prevent fibrinolysis, and reoperations for bleeding poses a dilemma. One would optimally balance these factors to minimize patient risk. Uncertainty in defining an optimal transfusion threshold, a trigger for reoperation, and a strategy for use of pharmaceuticals is evidenced by the considerable variability in clinical practice worldwide. ${ }^{1,2}$ Therefore, to gain insight to inform surgical practice, we have brought together current knowledge of the association of preoperative anemia, intraoperative anemia, blood transfusion, and measures to address blood loss with adverse outcomes after cardiac surgery.

\section{PREOPERATIVE ANEMIA AND OUTCOMES}

The World Health Organization defines anemia as a hemoglobin level less than $13 \mathrm{~g} / \mathrm{dL}$ in men and less than $12 \mathrm{~g} / \mathrm{dL}$ in women. By that measure, prevalence of preoperative anemia in patients undergoing cardiac surgery ranges from $16 \%$ to $54 \%$, with severe anemia (hemoglobin $<10 \mathrm{~g} / \mathrm{dL}$ ) in $5.5 \% .^{3-5}$ Patients presenting with low hemoglobin are more susceptible to end-organ ischemia; however, oxygen demands on CPB vary, and it is unclear what hemoglobin level is adequate. Nonetheless, several large observational studies suggest that preoperative anemia is associated with increased noncardiac morbidity and mortality after CPB (Table 1).

Zindrou and colleagues ${ }^{6}$ performed an observational study of 2059 patients undergoing isolated coronary artery bypass grafting $(\mathrm{CABG})$ that showed that patients with a preoperative hemoglobin of $10 \mathrm{~g} / \mathrm{dL}$ or less had a 5 -fold higher in-hospital mortality than those with a greater hemoglobin

From the Department of Thoracic and Cardiovascular Surgery ${ }^{\mathrm{a}}$ and Department of Cardiothoracic Anesthesia, ${ }^{b}$ Heart and Vascular Institute, and Department of Quantitative Health Sciences, ${ }^{c}$ Research Institute, Cleveland Clinic, Cleveland, Ohio.

This study was supported in part by the Kenneth Gee and Paula Shaw, PhD, Chair in Heart Research, held by Dr Blackstone.

Disclosures: Authors have nothing to disclose with regard to commercial support.

Received for publication July 13, 2011; revisions received Feb 17, 2012; accepted for publication April 13, 2012; available ahead of print June 19, 2012.

Address for reprints: Colleen G. Koch, MD, MS, MBA, Cleveland Clinic, Department of Cardiothoracic Anesthesia, 9500 Euclid Avenue/Desk J4-331, Cleveland, OH 44195 (E-mail: kochc@ccf.org).

J Thorac Cardiovasc Surg 2012;144:538-46

$0022-5223 / \$ 36.00$

Copyright (c) 2012 by The American Association for Thoracic Surgery

doi: $10.1016 /$ j.jtcvs.2012.04.014 concentration. This was confirmed by multivariable analysis. However, this study may have been confounded by RBC transfusion, which was not considered in the analysis.

Likewise, van Straten and colleagues ${ }^{5}$ from the Dutch Central Bureau for Statistics performed an observational study of 10,626 patients who underwent CABG. Preoperative anemia, as defined by the World Health Organization, was an independent risk factor for increased early ( $<30$ days) mortality and higher degree of preoperative anemia for higher late mortality. Preoperative hemoglobin of $14.5 \mathrm{~g} / \mathrm{dL}$ or greater in men and $13.5 \mathrm{~g} / \mathrm{dL}$ in women was associated with an $88 \%$ survival at 8 years, whereas a value less than $12 \mathrm{~g} / \mathrm{dL}$ in men and less than $11 \mathrm{~g} / \mathrm{dL}$ in women was associated with a $55 \%$ survival at 8 years. This study did not factor intraoperative anemia or use of RBC transfusion into the analysis.

To account for transfusion as a potential confounder, Ranucci and colleagues ${ }^{7}$ reviewed 3003 consecutive patients undergoing isolated $\mathrm{CABG}$ without perioperative $\mathrm{RBC}$ transfusion and found no association between preoperative anemia and postoperative mortality. However, they reported a 5-fold greater unadjusted occurrence of major morbidity in patients with a preoperative hematocrit (HCT) of $33 \%$ or less versus $42 \%$ or greater. After risk adjustment, preoperative HCT and lowest HCT on CPB were associated with an increased postoperative occurrence of prolonged ventilation, renal insufficiency, stroke, and reoperation.

Several additional studies have identified an association between preoperative anemia and postoperative morbidity. A multicenter observational study by Kulier and colleagues $^{4}$ demonstrated that preoperative anemia (hemoglobin $<13 \mathrm{~g} / \mathrm{dL}$ ) was associated with increased neurologic, renal, and gastrointestinal complications. Anemia was not associated with more cardiac complications, although these events were related to perioperative RBC transfusion. De Santo and colleagues ${ }^{8}$ studied a cohort of 1214 cardiac surgical patients and found that preoperative anemia was an independent risk factor for postoperative renal insufficiency. Karkouti and colleagues ${ }^{9}$ evaluated 3500 consecutive cardiac surgery cases for the association of preoperative anemia (hemoglobin $<12 \mathrm{~g} / \mathrm{dL}$ ) with the composite outcome of death, stroke, and acute renal insufficiency. Adjusted odds ratio for the composite outcome was 1.8 for patients with preoperative anemia. Kazmierski and colleagues ${ }^{10}$ examined the relationship of preoperative anemia to the prevalence 


$$
\begin{aligned}
& \text { Abbreviations and Acronyms } \\
& \begin{aligned}
\text { CABG } & =\text { coronary artery bypass grafting } \\
\text { CPB } & =\text { cardiopulmonary bypass } \\
\text { EPO } & =\text { erythropoietin } \\
\text { FFP } & =\text { fresh-frozen plasma } \\
\text { HCT } & =\text { hematocrit } \\
\text { HIF } & =\text { hypoxia-inducible factor } \\
\text { NOS } & =\text { nitric oxide synthase } \\
\text { RBC } & =\text { red blood cell }
\end{aligned}
\end{aligned}
$$

of postoperative delirium (16\%), adjudicated by 2 independent psychiatrists, on the basis of the criteria in the Diagnostic and Statistical Manual of Mental Disorders, Fourth Edition. After adjustment for various risk factors, preoperative anemia was an independent risk factor for postoperative delirium.

The association of preoperative anemia with adverse postoperative events is not limited to cardiac surgery. In a study of 227,425 patients undergoing a variety of general and vascular surgical procedures reported in the American College of Surgeons' National Surgical Quality Improvement Program database, Musallam and colleagues ${ }^{11}$ found that even mild levels of anemia (HCT $29 \%$ to $36 \%$ in women and $29 \%$ to $39 \%$ in men) were associated with a substantial increase in adverse events. Anemic patients had a $42 \%$ higher adjusted mortality and $35 \%$ higher adjusted composite morbidity than nonanemic patients. A retrospective analysis of 7759 noncardiac surgical cases by Beattie and colleagues ${ }^{12}$ showed a prevalence of anemia (hemoglobin $<12 \mathrm{~g} / \mathrm{dL}$ ) of $39 \%$ that was associated with a 2.3-fold higher risk of death.

Thus, preoperative anemia places patients undergoing cardiac and noncardiac surgery at risk of postoperative mortality and morbidity, and the magnitude of that risk increases with increasing degree of preoperative anemia. Sorting out the relative contribution of preoperative, intraoperative, and postoperative anemia to this risk, in addition to the contribution of RBC transfusion and management of anemia, is difficult. Nonetheless, preoperative anemia should raise the suspicion that these patients will be at higher risk for adverse postoperative outcomes.

\section{Managing Preoperative Anemia}

How can one best manage patients with preoperative anemia without the use of blood transfusions? There are 2 aspects to this: one is to optimize hemoglobin level and the other is to avoid risk factors for bleeding. For the former, reversible causes of anemia, such as occult gastrointestinal bleeding, should be ruled out and addressed. Surgery should be delayed to allow correction of anemia whenever possible. Patients with volume overload should be diuresed adequately, and iron supplementation should be instituted.
Elective operations should be delayed for at least 2 weeks to allow optimization of preoperative hemoglobin.

Administration of erythropoietin (EPO) has been suggested as a way to promote erythropoiesis in anemic patients several days before cardiac surgery. ${ }^{13}$ Although recombinant EPO increases RBC mass, it has not been demonstrated to reduce the need for RBC transfusion in cardiac surgery, ${ }^{14}$ and for specific patient populations, some have expressed concern that it may contribute to adverse outcomes. ${ }^{15,16}$ EPO may lead to overcorrection of anemia in patients with chronic kidney disease and is associated with increased occurrence of cardiovascular events. ${ }^{17,18}$ Other side effects include worsening hypertension and increased risk of thrombosis. ${ }^{19}$

Moreover, the 2011 update to the Society of Thoracic Surgeons recommendations on blood conservation address several interventions for reducing risk of bleeding in highrisk patients undergoing cardiac surgery. ${ }^{13}$ These should be applied to patients with preoperative anemia. Although a complete review of this topic is beyond the scope of this article, several important points should be highlighted. For instance, drugs that inhibit platelet P2Y12 receptors, such as clopidogrel, ticlopidine, prasugrel, and ticagrelor, should be avoided when feasible. Desmopressin should be considered for patients with evidence of platelet dysfunction. Use of platelets or fresh-frozen plasma (FFP) must be balanced against the hazards of transfusing blood products. Factor IX concentrates may be helpful in patients with hemophilia B or for prophylaxis in Jehovah's Witness patients who are anemic at baseline. ${ }^{20}$ Further discussion of risks and benefits of RBC transfusions is detailed below.

\section{INTRAOPERATIVE ANEMIA AND OUTCOMES}

Several factors contribute to intraoperative anemia: CPB priming volume, crystalloid solutions, and bleeding due to technical factors or coagulopathy. Investigators have demonstrated that the lowest HCT on CPB is associated with adverse patient outcomes. Habib and colleagues ${ }^{21}$ reported that postoperative morbidity and mortality were greater in patients with a nadir HCT less than $22 \%$. This was supported by their multivariable analysis; however, they did not control for RBC transfusion. Their subsequent study of 1760 patients undergoing isolated CABG concluded that intraoperative HCT less than $24 \%$ was associated with increased renal insufficiency independently of use of RBC transfusion. ${ }^{22}$ This effect was exacerbated by increased CPB duration and transfusion.

Ranucci and colleagues ${ }^{7}$ performed an investigation of nontransfused cardiac surgical patients and showed that nadir HCT on CPB was a risk factor for postoperative major morbidity but not mortality. The regional observational study by Defoe and colleagues ${ }^{23}$ of 6980 patients undergoing isolated $\mathrm{CABG}$ identified nadir HCT during CPB as a risk factor for in-hospital mortality, intra- or postoperative 
TABLE 1. Investigations examining effect of preoperative anemia on postoperative outcomes

\begin{tabular}{|c|c|c|c|}
\hline Investigation & Design & $\mathbf{n}$ & Effect \\
\hline Zindrou et $\mathrm{al}^{6}$ & Observational & 2059 & Increased mortality \\
\hline Hung et $\mathrm{al}^{3}$ & Observational & 2688 & $\begin{array}{l}\text { Increased transfusion } \\
\text { requirement, ICU } \\
\text { stay, and mortality }\end{array}$ \\
\hline van Straten et al $1^{5}$ & Observational & 10,626 & Increased mortality \\
\hline Ranucci et $\mathrm{al}^{7}$ & Observational & 3003 & $\begin{array}{l}\text { Prolonged ventilation, } \\
\text { renal insufficiency, } \\
\text { stroke, reoperations }\end{array}$ \\
\hline Karkouti et $\mathrm{al}^{9}$ & Observational & 3500 & $\begin{array}{l}\text { Increased in-hospital } \\
\text { death, stroke, or } \\
\text { acute kidney injury }\end{array}$ \\
\hline Kulier et $\mathrm{al}^{4}$ & Observational & 5065 & $\begin{array}{l}\text { Neurologic, renal, } \\
\text { and GI complications }\end{array}$ \\
\hline De Santo et $\mathrm{al}^{8}$ & Observational & 1214 & $\begin{array}{l}\text { Postoperative renal } \\
\text { insufficiency }\end{array}$ \\
\hline Kazmierski et al ${ }^{10}$ & Observational & 563 & Postoperative delirium \\
\hline
\end{tabular}

$I C U$, Intensive care unit; $G I$, gastrointestinal.

placement of an intra-aortic balloon pump, and return to CPB. Adjusted mortality for patients with an HCT less than $19 \%$ was approximately twice that of patients with a nadir HCT $25 \%$ or greater $(3.9 \%$ vs $1.6 \% ; P<.001)$.

In a randomized trial by Jonas and colleagues,${ }^{24} 74$ patients undergoing $\mathrm{CPB}$ for congenital disorders were assigned to a lower HCT strategy $(22 \% \pm 2.9 \%)$ and 73 patients were assigned to a higher strategy $(27.8 \% \pm$ $3.2 \%)$. In an intent-to-treat analysis, the lower HCT group had greater cardiac dysfunction and serum lactate levels and higher total body water. At 1 year, Psychomotor Development Index scores were lower in the lower HCT group. Mortality was similar.

Swaminathan and colleagues ${ }^{25}$ showed that nadir HCT during CPB was associated with higher peak change in serum creatinine and highest postoperative creatinine. Other risk factors for postoperative change in creatinine included higher preoperative creatinine, lower preoperative HCT, and $\mathrm{RBC}$ transfusion.
Karkouti and colleagues ${ }^{26}$ investigated the influence of nadir HCT during CPB on postoperative stroke in more than 10,000 patients requiring CPB for cardiac surgical procedures. Prevalence of postoperative stroke was $1.0 \%$ $(\mathrm{n}=110 / 10,949)$. Patients experiencing a stroke had a lower nadir HCT $(21 \pm 3.0 \mathrm{~g} / \mathrm{dL})$ than those who did not $(23 \pm$ $5.0 \mathrm{~g} / \mathrm{dL}$ ). After risk adjustment, each percentage decrease in nadir HCT was associated with a $10 \%$ increase in risk of a postoperative stroke $(P=.002)$. RBC transfusion was also a risk factor for stroke. ${ }^{26}$

Yet not all studies have shown that intraoperative anemia is associated with adverse patient outcomes. von Heymann and colleagues ${ }^{27}$ randomized 54 patients undergoing normothermic CPB to a mean HCT of $20 \%$ versus $25 \%$. Calculated oxygen delivery in the low versus high HCT groups was similar: $647 \pm 200$ versus $760 \pm 180$ $\mathrm{mL} / \mathrm{m}^{2} / \mathrm{min}$, respectively. Oxygen consumption, blood lactate levels, cardiac index, vasopressor requirements, and morbidities, including stroke, renal failure, and respiratory failure, were similar. A randomized study by Berger and colleagues $^{28}$ exposed 23 patients to an HCT range of $19 \%$ to $21 \%$ and 24 patients to an HCT range of $24 \%$ to $26 \%$. They found that gastrointestinal permeability and expression of inflammatory cytokines were similar. However, neither study was powered for detecting a difference in these outcomes.

Evidence supports the notion that intraoperative anemia is associated with adverse neurologic, renal, cardiac, and pulmonary outcomes. Increased length of stay and possibly increased mortality are also associated with a lower nadir HCT (Table 2). A summary of data points from the literature suggests an inflection point around an HCT of $20 \%$ to $24 \%$, below which morbidity and mortality increase substantially (Figure 1).

\section{Managing Intraoperative Anemia}

Among methods used to prevent or correct intraoperative anemia in patients undergoing cardiac surgery are antifibrinolytics, cell salvage, ultrafiltration, and RBC transfusion.

TABLE 2. Investigations examining effect of intraoperative anemia on postoperative outcomes

\begin{tabular}{|c|c|c|c|}
\hline Groups & Design & $\mathbf{n}$ & Effect \\
\hline Habib et $\mathrm{al}^{21}$ & Observational & 5000 & Increased mortality and pulmonary, neurologic, renal, and cardiac morbidity \\
\hline Habib et $\mathrm{al}^{22}$ & Observational & 1760 & Increased renal injury \\
\hline Ranucci et $\mathrm{al}^{7}$ & Observational & 3003 & $\begin{array}{l}\text { Major morbidity: prolonged ventilation, surgical reoperation, mediastinitis, } \\
\text { renal dysfunction, stroke }\end{array}$ \\
\hline DeFoe et $\mathrm{al}^{23}$ & Observational & 6980 & Mortality, low output heart failure \\
\hline Jonas et $\mathrm{al}^{24}$ & Randomized controlled trial & 147 & $\begin{array}{l}\text { Decreased cardiac index and psychomotor development; increased serum } \\
\text { lactate and total body water }\end{array}$ \\
\hline Swaminathan et $\mathrm{al}^{25}$ & Observational & 1404 & Renal insufficiency \\
\hline Karkouti et $\mathrm{al}^{26}$ & Observational & 10,949 & Stroke \\
\hline Bahrainwala et al $^{58}$ & Observational & 617 & Increased risk of stroke \\
\hline von Heymann et $\mathrm{al}^{27}$ & Randomized controlled trial & 54 & Similar oxygen delivery and morbidity \\
\hline Berger et $\mathrm{al}^{28}$ & Randomized controlled trial & 47 & Similar GI permeability and inflammatory response \\
\hline
\end{tabular}

GI, Gastrointestinal. 


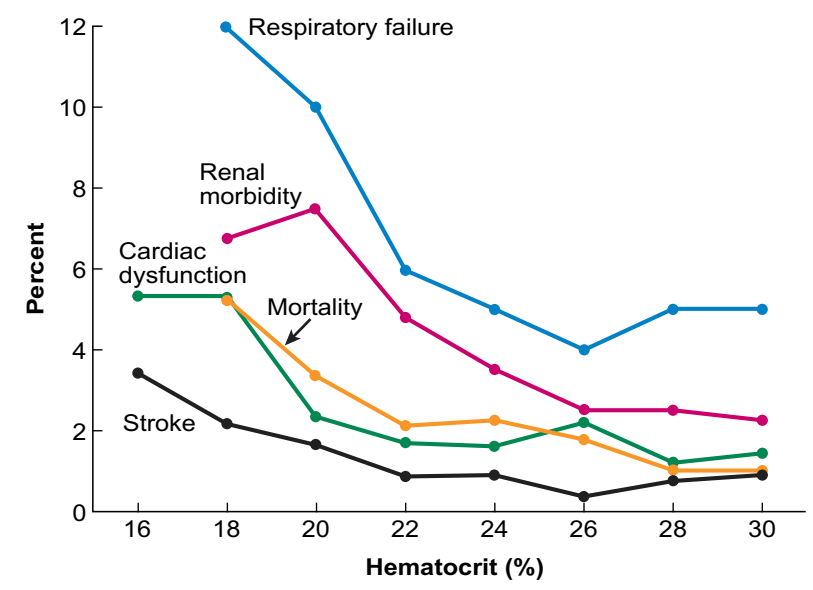

FIGURE 1. Composite graph summarizing the effects of intraoperative anemia on morbidity and mortality. Data points were derived from the literature as follows: Respiratory failure: Habib and colleagues $2003,{ }^{21}$ prevalence of prolonged ventilation as a function of intraoperative HCT. Cardiac morbidity: (1) Habib and colleagues $2003,{ }^{21}$ average of the prevalence of cardiac arrest, heart failure, and intra-aortic balloon pump as a function of intraoperative HCT; (2) Defoe and colleagues 2001, ${ }^{23}$ average of the prevalence of intra-aortic balloon pumping and return to $\mathrm{CPB}$ as a function of intraoperative HCT. Renal morbidity: (1) Habib and colleagues 2005, ${ }^{22}$ acute renal failure as a function of intraoperative HCT; (2) Habib and colleagues $2003,{ }^{21}$ prevalence of acute renal failure as a function of intraoperative HCT values. Stroke: (1) Habib and colleagues $2003,{ }^{21}$ prevalence of stroke as a function of intraoperative HCT values; (2) Karkouti and colleagues, ${ }^{26}$ prevalence of stroke as a function of intraoperative HCT values. Mortality: (1) Habib and colleagues $2003,{ }^{21}$ intraoperative mortality as a function of intraoperative HCT values; (2) DeFoe and colleagues $2001,{ }^{23}$ intraoperative mortality as a function of intraoperative HCT values.

If anemia leads to adverse outcomes after cardiac surgery, these methods should decrease morbidity and mortality. Yet several studies have reported increased morbidity associated with many of these interventions.

The Society of Thoracic Surgeons blood conservation update gave a class I recommendation for the use of lysine analogues during cardiac surgery. ${ }^{13}$ Antifibrinolytics reduce blood loss and RBC use in cardiac surgical patients. ${ }^{29}$ E-aminocaproic acid and tranexamic acid are the most commonly used agents; aprotonin is no longer used in adult cardiac surgery because of an unfavorable safety profile. ${ }^{30-32}$ A meta-analysis by Brown and colleagues ${ }^{33}$ demonstrated that all 3 agents were equally effective in decreasing RBC use, but none offered any significant benefit in reducing mortality, stroke, myocardial infarction, or renal failure. A number of other blood conservation techniques have been used to decrease blood loss and RBC use in cardiac surgery. For instance, several studies have shown that ultrafiltration reduces postoperative blood transfusions, fluid overload, and pulmonary injury ${ }^{34-37}$; however, none demonstrated a reduction in mortality. In addition, a metaanalysis by Wang and colleagues ${ }^{38}$ reviewed 31 randomized trials involving 2282 patients and showed that intraoperative RBC salvage reduced RBC transfusions but not morbidity or mortality. Although pharmaceutical agents and blood salvage techniques can be useful in certain highrisk groups, reducing blood loss does not always equate to improved outcomes. In fact, some agents, such as aprotinin, result in adverse outcomes that offset the benefits of reduced blood loss and transfusions.

Moreover, patients can develop coagulopathies as a result of $\mathrm{CPB}$, which may exacerbate anemia. Platelet counts and function are often reduced after CPB. In a large-scale observational study of 32,298 cardiac surgical patients, McGrath and colleagues ${ }^{39}$ showed that platelet transfusions were not associated with increased morbidity or mortality after adjusting for RBC transfusions. In a propensity-matched cohort analysis, platelet transfusions were actually associated with decreased neurologic, infectious, and composite morbidity. Karkouti and colleagues ${ }^{40}$ reached a similar conclusion in a study of 11,459 patients undergoing cardiac surgery at the University of Toronto. In a smaller study, Spiess and colleagues ${ }^{41}$ suggested that platelets were associated with increased morbidity, although the analysis was confounded by RBC use. Thus, if platelets are deemed necessary for persistent microvascular bleeding in the operating room, they should be given. This is not to advocate the prophylactic use of platelets, which has not been shown to be helpful in the past. ${ }^{42,43}$

Platelet plasmapheresis is an interesting alternative but requires considerable expertise and has yielded conflicting results. ${ }^{13,44-47}$ Prophylactic use of FFP does not reduce blood loss and exposes patients to the morbidity risk. ${ }^{48-50}$ On the other hand, a combination of an elevated international normalized ratio at the conclusion of $\mathrm{CPB}$, along with clinical evidence of refractory bleeding, may justify FFP transfusion. Thus, correcting intraoperative coagulopathies with blood component therapy can prevent exacerbation of anemia when used appropriately in cases of overt coagulopathic bleeding.

\section{POSTOPERATIVE ANEMIA AND OUTCOMES}

The immediate postoperative state after cardiac and major noncardiac surgery is characterized by a stress response and variable deficits in tissue perfusion that precede a period of tissue healing and recovery. Although oxygen supply and demand can be unpredictable during this time, it is evident that anemia is relatively well tolerated compared with the ill effects of liberal transfusion strategies. ${ }^{51-54}$ To clarify the effects of postoperative anemia in nontransfused patients, Carson and colleagues ${ }^{55}$ studied 300 Jehovah's Witness patients with cardiovascular disease undergoing cardiac and noncardiac surgery. They found that lower postoperative hemoglobin values were associated with increased risk of death or serious morbidity. In a separate but similar postoperative study of postoperative Jehovah's Witness patients, 
their group noted a 2-fold increase in the odds ratio of death for every $1-\mathrm{g}$ decrease in postoperative hemoglobin less than $8.0 \mathrm{~g} / \mathrm{dL} .^{56}$

Westenbrink and colleagues ${ }^{57}$ studied 2553 patients undergoing CABG and found a prevalence of sustained postoperative anemia beyond 50 days in $44 \%$ of patients. It was associated with an increase in major adverse cardiac events. In addition, every $1 \mathrm{mg} / \mathrm{dL}$ decrease in hemoglobin was associated with a $13 \%$ increase in cardiovascular events and $22 \%$ increase in all-cause mortality. Their multivariable model accounted for preoperative hemoglobin and transfusions but not intraoperative nadir HCT. In a study of 689 patients undergoing any type of heart operation requiring $\mathrm{CPB}$, Johns Hopkins Hospital investigators ${ }^{58}$ found that post-CPB HCT values were related to increased occurrence of postoperative stroke independently of RBC transfusion. This study also did not account for nadir HCT, but did factor in preoperative hemoglobin in the multivariable analysis.

The observational study by Ranucci and colleagues ${ }^{59}$ of 172 patients who did not receive transfusions during cardiac surgical procedures found that patients with a hemoglobin less than $10 \mathrm{~g} / \mathrm{dL}$ had a worse performance on the 6-minute walk test than patients with higher values. This difference resolved, however, after a normal rehabilitation period without the use of RBC transfusion. From the limited observational data available, it seems that postoperative hemoglobin is independently associated with an increase in adverse events. The difficulty with interpreting these results is lack of control for the spectrum of anemia throughout cardiac surgery, including preoperative anemia and nadir intraoperative HCTs, although most of these studies did control for the effects of RBC transfusions.

\section{Managing Postoperative Anemia}

How does one best manage postoperative anemia? Although the risks and benefits of RBC transfusions are discussed in detail below, it is clear that patients tolerate a reasonable level of anemia without RBC transfusions. Several safe practices exist to prevent worsening anemia. Hemodilution should be avoided, and patients should be adequately diuresed. Excessive blood draws should be limited. Coagulation studies should be obtained and any abnormalities corrected only if there is evidence of ongoing blood loss. The anemia that develops from surgical oozing coupled with reoperations, when required, can contribute significantly to increased morbidity. ${ }^{60}$ Thus, the importance of intraoperative hemostasis cannot be overstated. Use of EPO in the postoperative setting is subject to the same concerns discussed under "Managing Preoperative Anemia" earlier in this text.

\section{ANEMIA-INDUCED INJURY AND CELLULAR ADAPTATION}

If left unchecked, anemia leads to decreased cellular oxygen, increased acidosis, and abnormal calcium balance that culminate in activation of programmed and necrotic cellular death pathways. ${ }^{61}$ Yet cells have a remarkable ability to resist the effects of anemia through activation of hypoxia-inducible factor (HIF) $1-\alpha$ protein, the master regulator of cellular responses to oxygen deprivation. ${ }^{62} \mathrm{HIF}$ 1- $\alpha$ upregulates a number of enzymes involved in oxygen delivery and cell survival, including EPO, vascular endothelial growth factor, nitric oxide synthase (NOS), glucose transporter-1, and heme oxygenase- $1 .{ }^{63}$ NOS has gained much attention as a critical effector of HIF-mediated responses to anemia. Through the synthesis of nitric oxide, it has vasodilatory, antioxidant, and anti-inflammatory properties. When exposed to anemia, mice lacking neuronal NOS are unable to stabilize HIF $1-\alpha$ protein products and have greater mortality than wild-type mice. ${ }^{64}$ Hare and colleagues ${ }^{65}$ reported rats hemodiluted to a final hemoglobin of $5 \mathrm{~g} / \mathrm{dL}$ showed compensatory increases in cerebral blood flow as a result of rapid increases in neuronal NOS mRNA. Likewise, McLaren and colleagues ${ }^{66}$ found increases in cerebral cortical inducible NOS and neuronal NOS protein levels in rats exposed to hemodilutioninduced anemia. Given the adverse effects of RBC transfusion, it is important to continue developing our understanding of molecular mechanisms involved in the cellular response to anemia. Development of sensitive markers that would indicate when a cell's compensatory measures are at the point of being overwhelmed would allow a more tailored approach to blood transfusions.

\section{TRANSFUSION-INDUCED INJURY AND RISK-BENEFIT}

Practice patterns and recommendations for blood transfusion have evolved over approximately 6 decades. It was once deemed safe and standard to transfuse critically ill patients liberally in an effort to enhance oxygen supply and improve outcomes. Yet increasing evidence suggests that transfusions, although beneficial to some patients, may worsen outcomes in others. Cardiac surgical patients consume a substantial proportion of the blood products used in most hospitals. A recent investigation by Hung and colleagues $^{3}$ reported more than a 3 -fold increase in the risk for perioperative RBC transfusion and higher financial costs among patients with preoperative anemia. Thus, there has been a considerable impetus to assess the effects of blood transfusions on outcomes of patients undergoing CPB. Hajjar and colleagues ${ }^{51}$ randomized 257 patients to a liberal transfusion strategy using an $\mathrm{HCT}$ of $30 \%$ as a transfusion trigger. In the conservative arm $(n=249)$, the trigger for transfusion was an $\mathrm{HCT}$ of $24 \%$. In the liberal transfusion group, $78 \%$ received $\mathrm{RBCs}$, compared with $47 \%$ of patients in the conservative transfusion arm. Thirty-day allcause mortality and severe morbidity were similar between groups, although there was a trend toward better survival in the conservative arm; however, increasing number of units 
transfused was an independent risk factor for clinical complications regardless of transfusion strategy.

A Cleveland Clinic study of patients who underwent isolated CABG demonstrated that each unit of perioperative RBC transfused was associated with an incremental increase in both early and late risk-adjusted mortality (Figure 2). ${ }^{67}$ In a separate study of 11,963 patients undergoing isolated $\mathrm{CABG}$, after risk adjustment for different characteristics of those receiving and not receiving transfusions, RBC transfusion was associated with a dose-dependent increased risk for every postoperative morbid event, including mortality, renal failure, prolonged ventilatory support, serious infection, cardiac complications, and neurologic events (Figure 3). ${ }^{68}$

In a prospective cohort study, 7321 patients completed a pre- and postoperative Duke Activity Status Index survey at 6 and 12 months to assess the influence of perioperative transfusions on functional status. ${ }^{69}$ Patients who received transfusions had incrementally worse functional status with each RBC unit transfused. Surgenor and colleagues ${ }^{70}$ evaluated 8004 consecutive patients who underwent CPB and noted that those who were older and smaller and who had more comorbidities stood a greater chance of receiving a blood transfusion. ${ }^{70}$ Multivariable analysis demonstrated that both RBCs and anemia were independently associated with low-output heart failure. Intraoperative receipt of 1 or 2 units of RBC was associated with a $27 \%$ increase in risk of heart failure compared with no transfusion.

Furnary and colleagues ${ }^{71}$ analyzed data from a prospective multicenter database that included 15,174 cardiac surgical patients and found that patients who received 5 units of RBC transfusion had a 4-fold greater occurrence of renal failure than those who did not receive RBC transfusion. On multivariable analysis, $\mathrm{RBC}$ transfusion was independently associated with acute renal failure.

Studies have also associated RBC transfusion with an increased risk of cardiac rhythm, infectious, and respiratory complications. A study of 5841 cardiac surgical patients showed that intensive care unit RBC transfusion was associated with an increased risk of new-onset atrial fibrillation (46\% vs $38 \%))^{72}$ In a cohort investigation by Chelemer and colleagues, ${ }^{73} \mathrm{RBC}$ transfusion was associated with a higher risk of bacterial infections in a dose-dependent manner: $4.8 \%$ for no packed RBC transfusion, $15 \%$ with 1 or 2 units, $22 \%$ with 3 to 5 units, and $29 \%$ with 6 or more units. In a large observational study of 15,592 patients, Banbury and colleagues $^{48}$ reported an association between RBC transfusion and higher risk-adjusted occurrence of septicemia or bacteremia, as well as superficial and deep sternal wound infections. Koch and colleagues ${ }^{50}$ demonstrated that cardiac surgical patients receiving RBC transfusions had more risk-adjusted pulmonary complications: respiratory distress, respiratory failure, longer intubation times, acute respiratory distress syndrome, and reintubation.

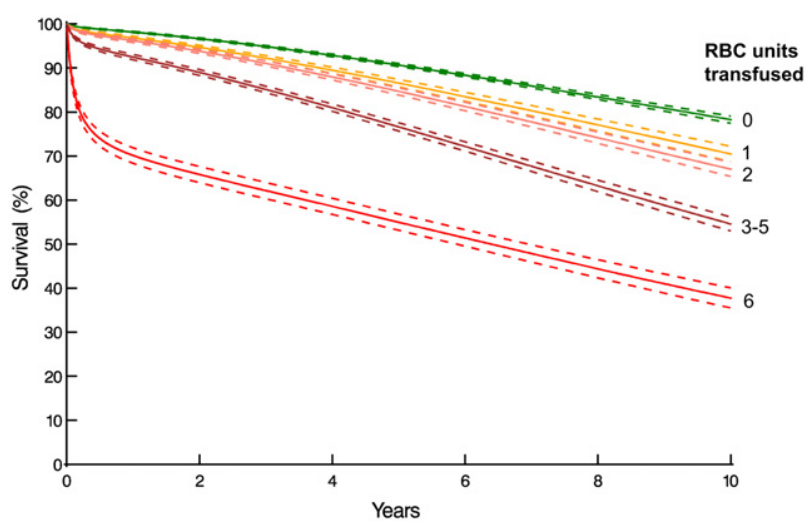

FIGURE 2. Survival after isolated CABG stratified by number of RBC units transfused. Increasing number of perioperative RBC transfusions results in incremental decreases in postoperative survival. ${ }^{67}$ Solid lines are parametric estimates enclosed within dashed $68 \%$ confidence limits. $R B C$, Red blood cell.

Several factors are thought to contribute to the observed association of RBC transfusion and adverse outcomes. Transfusion-related acute lung injury, transfusion-related circulatory overload, and immunomodulation are among well-recognized complications associated with RBC transfusion. ${ }^{74-79}$ Increasing duration of RBC storage is another factor thought to contribute to adverse clinical effects of RBC transfusion. ${ }^{80-82}$

Changes in the RBC product with increasing storage include decreases in 2,3-diphosphoglycerate and $\mathrm{pH}$ along with increases in potassium, free hemoglobin, and lactate concentrations. ${ }^{83}$ Changes in structural characteristics leading to decreased RBC deformability and the metabolic changes that accompany increasing storage duration are referred to as the "storage lesion." These changes in the

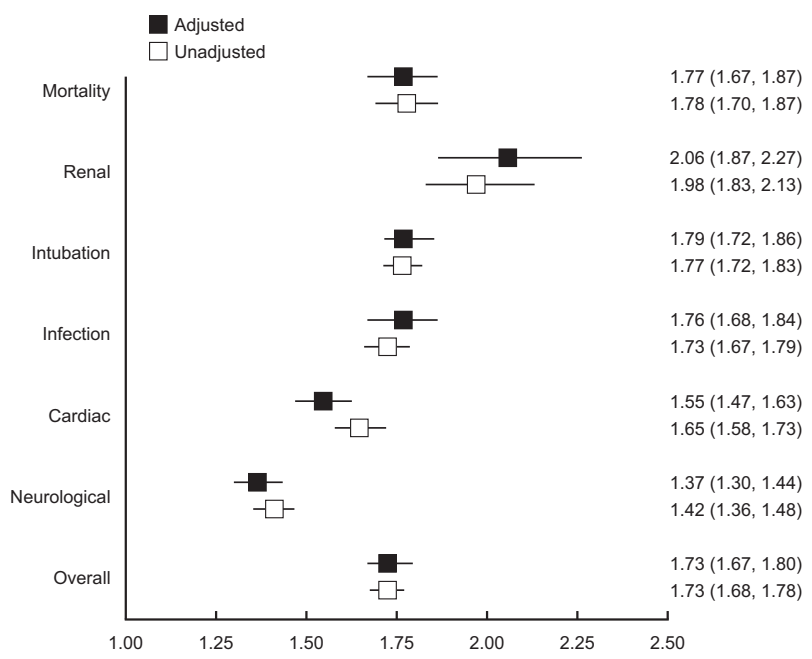

FIGURE 3. Forest plot demonstrating effects of RBC transfusions on patient outcomes after cardiac surgery. ${ }^{68}$ Horizontal axis represents odds ratio for each morbid outcome. 


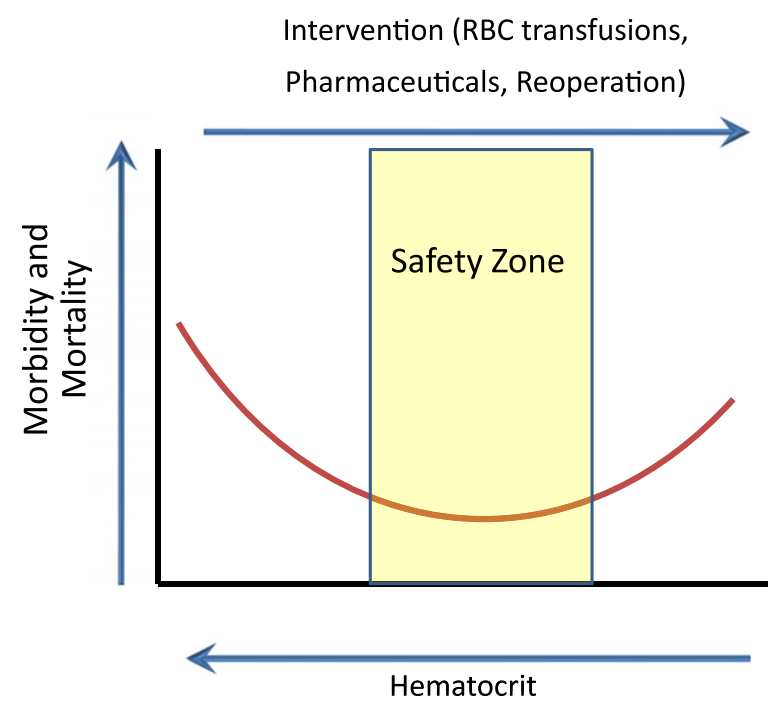

FIGURE 4. Pictorial representation of a U-shaped relationship that exists between adverse events related to degree of anemia on the left and degree of intervention on the right. The "safety zone" at the bottom of the curve reflects a balance between tolerable anemia and interventions to correct anemia. $R B C$, Red blood cell.

RBC product may contribute to some of the observed adverse clinical outcomes associated with transfusion. ${ }^{84-86}$ A recent laboratory investigation by Sweeney and colleagues ${ }^{87}$ reported that increasing RBC storage was related to development of RBC-derived microparticles that could facilitate thrombin generation. Other changes to the $\mathrm{RBC}$ product occur immediately after routine storage, such as reductions in RBC S-nitrosohemoglobin levels, which may have implications for oxygen delivery to the microcirculation. ${ }^{83,88}$ Roback and colleagues ${ }^{89}$ reported that reductions in nitric oxide availability with $\mathrm{RBC}$ storage may lead to reduced blood flow because of impairment in the vasodilation response to hypoxia. Current ongoing randomized controlled trials on storage duration and outcome in cardiac surgery will be able to more definitively address the role of storage duration and patient morbidity.

\section{CONCLUSIONS}

Preoperative and intraoperative anemia contribute to increased morbidity and mortality in patients undergoing cardiac surgery. Interventions that prevent or correct anemia, such as RBC transfusion and pharmaceutical agents, may increase patient risk. We envision a U-shaped relationship whereby worsening anemia contributes to increased morbidity and mortality along the left of the x-axis and aggressive use of interventions contributes to adverse outcomes along the right of the x-axis (Figure 4). At the bottom of the $U$ exists a balance between risks of moderate levels of anemia that are well tolerated and both risks and benefits of judicious use of interventions to correct or prevent anemia. Patients undergoing cardiac surgery ideally should be managed within this zone of minimum risk, without venturing into either extreme. By recognizing that preoperative anemia influences morbidity and heightens risk for perioperative RBC transfusion, all efforts should be made to investigate and correct anemia before surgical intervention. Future research should continue to clarify this zone that balances the adverse effects of anemia and benefits and risks of interventions to correct it.

\section{References}

1. Snyder-Ramos SA, Mohnle P, Weng YS, Bottiger BW, Kulier A, Levin J, et al. The ongoing variability in blood transfusion practices in cardiac surgery. Transfusion. 2008;48:1284-99.

2. Bennett-Guerrero E, Zhao Y, O'Brien SM, Ferguson TB Jr, Peterson ED, Gammie JS, et al. Variation in use of blood transfusion in coronary artery bypass graft surgery. JAMA. 2010;304:1568-75.

3. Hung M, Besser M, Sharples LD, Nair SK, Klein AA. The prevalence and association with transfusion, intensive care unit stay and mortality of preoperative anaemia in a cohort of cardiac surgery patients. Anaesthesia. 2011;66:812-8.

4. Kulier A, Levin J, Moser R, Rumpold-Seitlinger G, Tudor IC, Snyder-Ramos SA, et al. Impact of preoperative anemia on outcome in patients undergoing coronary artery bypass graft surgery. Circulation. 2007;116:471-9.

5. van Straten AH, Hamad MA, van Zundert AJ, Martens EJ, Schonberger JP, de Wolf AM. Preoperative hemoglobin level as a predictor of survival after coronary artery bypass grafting: a comparison with the matched general population. Circulation. 2009;120:118-25.

6. Zindrou D, Taylor KM, Bagger JP. Preoperative haemoglobin concentration and mortality rate after coronary artery bypass surgery. Lancet. 2002;359: 1747-8.

7. Ranucci M, Conti D, Castelvecchio S, Menicanti L, Frigiola A, Ballotta A, et al. Hematocrit on cardiopulmonary bypass and outcome after coronary surgery in nontransfused patients. Ann Thorac Surg. 2010;89:11-7.

8. De Santo L, Romano G, Della Corte A, de Simone V, Grimaldi F, Cotrufo M, et al. Preoperative anemia in patients undergoing coronary artery bypass grafting predicts acute kidney injury. J Thorac Cardiovasc Surg. 2009;138:965-70.

9. Karkouti K, Wijeysundera DN, Beattie WS. Risk associated with preoperative anemia in cardiac surgery: a multicenter cohort study. Circulation. 2008;117: 478-84.

10. Kazmierski J, Kowman M, Banach M, Fendler W, Okonski P, Banys A, et al. Incidence and predictors of delirium after cardiac surgery: results from The IPDACS Study. J Psychosom Res. 2010;69:179-85.

11. Musallam KM, Tamim HM, Richards T, Spahn DR, Rosendaal FR, Habbal A, et al. Preoperative anaemia and postoperative outcomes in non-cardiac surgery: a retrospective cohort study. Lancet. 2011;378:1396-407.

12. Beattie WS, Karkouti K, Wijeysundera DN, Tait G. Risk associated with preoperative anemia in noncardiac surgery: a single-center cohort study. Anesthesiology. 2009; 110:574-81.

13. Ferraris VA, Brown JR, Despotis GJ, Hammon JW, Reece TB, Saha SP, et al. 2011 update to the Society of Thoracic Surgeons and the Society of Cardiovascular Anesthesiologists blood conservation clinical practice guidelines. Ann Thorac Surg. 2011;91:944-82.

14. D'Ambra MN, Gray RJ, Hillman R, Jones JW, Kim HC, Rawitscher R, et al. Effect of recombinant human erythropoietin on transfusion risk in coronary bypass patients. Ann Thorac Surg. 1997;64:1686-93.

15. Unger EF, Thompson AM, Blank MJ, Temple R. Erythropoiesis-stimulating agents-time for a reevaluation. $N$ Engl J Med. 2010;362:189-92.

16. Besarab A, Bolton WK, Browne JK, Egrie JC, Nissenson AR, Okamoto DM, et al. The effects of normal as compared with low hematocrit values in patients with cardiac disease who are receiving hemodialysis and epoetin. $N$ Engl $J$ Med. 1998;339:584-90.

17. Singh AK, Szczech L, Tang KL, Barnhart H, Sapp S, Wolfson M, et al. Correction of anemia with epoetin alfa in chronic kidney disease. N Engl J Med. 2006; 355:2085-98.

18. Drueke TB, Locatelli F, Clyne N, Eckardt KU, Macdougall IC, Tsakiris D, et al. Normalization of hemoglobin level in patients with chronic kidney disease and anemia. N Engl J Med. 2006;355:2071-84. 
19. Felker GM, Adams KF Jr, Gattis WA, O'Connor CM. Anemia as a risk factor and therapeutic target in heart failure. J Am Coll Cardiol. 2004;44:959-66.

20. Bolliger D, Sreeram G, Duncan A, Molinaro RJ, Szlam F, Chen EP, et al. Prophylactic use of factor IX concentrate in a Jehovah's Witness patient. Ann Thorac Surg. 2009;88:1666-8.

21. Habib RH, Zacharias A, Schwann TA, Riordan CJ, Durham SJ, Shah A. Adverse effects of low hematocrit during cardiopulmonary bypass in the adult: should current practice be changed? J Thorac Cardiovasc Surg. 2003;125:1438-50.

22. Habib RH, Zacharias A, Schwann TA, Riordan CJ, Engoren M, Durham SJ, et al. Role of hemodilutional anemia and transfusion during cardiopulmonary bypass in renal injury after coronary revascularization: implications on operative outcome. Crit Care Med. 2005;33:1749-56.

23. DeFoe GR, Ross CS, Olmstead EM, Surgenor SD, Fillinger MP, Groom RC, et al. Lowest hematocrit on bypass and adverse outcomes associated with coronary artery bypass grafting. Northern New England Cardiovascular Disease Study Group. Ann Thorac Surg. 2001;71:769-76.

24. Jonas RA, Wypij D, Roth SJ, Bellinger DC, Visconti KJ, du Plessis AJ, et al. The influence of hemodilution on outcome after hypothermic cardiopulmonary bypass: results of a randomized trial in infants. J Thorac Cardiovasc Surg. 2003;126:1765-74.

25. Swaminathan M, Phillips-Bute BG, Conlon PJ, Smith PK, Newman MF, Stafford-Smith $\mathrm{M}$. The association of lowest hematocrit during cardiopulmonary bypass with acute renal injury after coronary artery bypass surgery. Ann Thorac Surg. 2003;76:784-92

26. Karkouti K, Djaiani G, Borger MA, Beattie WS, Fedorko L, Wijeysundera D, et al. Low hematocrit during cardiopulmonary bypass is associated with increased risk of perioperative stroke in cardiac surgery. Ann Thorac Surg. 2005; 80:1381-7.

27. von Heymann C, Sander M, Foer A, Heinemann A, Spiess B, Braun J, et al. The impact of an hematocrit of $20 \%$ during normothermic cardiopulmonary bypass for elective low risk coronary artery bypass graft surgery on oxygen delivery and clinical outcome-a randomized controlled study [ISRCTN35655335]. Crit Care. 2006;10:R58.

28. Berger K, Sander M, Spies CD, Weymann L, Buhner S, Lochs H, et al. Profound haemodilution during normothermic cardiopulmonary bypass influences neither gastrointestinal permeability nor cytokine release in coronary artery bypass graft surgery. Br J Anaesth. 2009;103:511-7.

29. Henry DA, Moxey AJ, Carless PA, O'Connell D, McClelland B, Henderson KM, et al. Anti-fibrinolytic use for minimising perioperative allogeneic blood transfusion. Cochrane Database Syst Rev. 2001;CD001886.

30. Fergusson DA, Hebert PC, Mazer CD, Fremes S, MacAdams C, Murkin JM, et al. A comparison of aprotinin and lysine analogues in high-risk cardiac surgery. $N$ Engl J Med. 2008;358:2319-31.

31. Mangano DT, Miao Y, Vuylsteke A, Tudor IC, Juneja R, Filipescu D, et al. Mortality associated with aprotinin during 5 years following coronary artery bypass graft surgery. JAMA. 2007;297:471-9.

32. Mangano DT, Tudor IC, Dietzel C. The risk associated with aprotinin in cardiac surgery. N Engl J Med. 2006;354:353-65.

33. Brown JR, Birkmeyer NJ, O'Connor GT. Meta-analysis comparing the effectiveness and adverse outcomes of antifibrinolytic agents in cardiac surgery. Circulation. 2007;115:2801-13.

34. Boodhwani M, Williams K, Babaev A, Gill G, Saleem N, Rubens FD. Ultrafiltration reduces blood transfusions following cardiac surgery: a meta-analysis. Eur J Cardiothorac Surg. 2006;30:892-7.

35. Hall TS, Brevetti GR, Skoultchi AJ, Sines JC, Gregory P, Spotnitz AJ. Re-exploration for hemorrhage following open heart surgery differentiation on the causes of bleeding and the impact on patient outcomes. Ann Thorac Cardiovasc Surg. 2001;7:352-7.

36. Mehta RH, Sheng S, O’Brien SM, Grover FL, Gammie JS, Ferguson TB, et al. Reoperation for bleeding in patients undergoing coronary artery bypass surgery: incidence, risk factors, time trends, and outcomes. Circ Cardiovasc Qual Outcomes. 2009;2:583-90.

37. Charalambous CP, Zipitis CS, Keenan DJ. Chest reexploration in the intensive care unit after cardiac surgery: a safe alternative to returning to the operating theater. Ann Thorac Surg. 2006;81:191-4.

38. Wang G, Bainbridge D, Martin J, Cheng D. The efficacy of an intraoperative cell saver during cardiac surgery: a meta-analysis of randomized trials. Anesth Analg. 2009; 109:320-30

39. McGrath T, Koch CG, Xu M, Li L, Mihaljevic T, Figueroa P, et al. Platelet transfusion in cardiac surgery does not confer increased risk for adverse morbid outcomes. Ann Thorac Surg. 2008;86:543-53.
40. Karkouti K, Wijeysundera DN, Yau TM, Callum JL, Meineri M, Wasowicz M et al. Platelet transfusions are not associated with increased morbidity or mortality in cardiac surgery. Can J Anaesth. 2006;53:279-87.

41. Spiess BD, Royston D, Levy JH, Fitch J, Dietrich W, Body S, et al. Platelet transfusions during coronary artery bypass graft surgery are associated with serious adverse outcomes. Transfusion. 2004;44:1143-8.

42. Harding SA, Shakoor MA, Grindon AJ. Platelet support for cardiopulmonary bypass surgery. J Thorac Cardiovasc Surg. 1975;70:350-3.

43. Simon TL, Akl BF, Murphy W. Controlled trial of routine administration of platelet concentrates in cardiopulmonary bypass surgery. Ann Thorac Surg. 1984;37: 359-64.

44. Jones JW, McCoy TA, Rawitscher RE, Lindsley DA. Effects of intraoperative plasmapheresis on blood loss in cardiac surgery. Ann Thorac Surg. 1990;49: 585-90.

45. Menges T, Welters I, Wagner RM, Boldt J, Dapper F, Hempelmann G. The influence of acute preoperative plasmapheresis on coagulation tests, fibrinolysis, blood loss and transfusion requirements in cardiac surgery. Eur J Cardiothorac Surg. 1997;11:557-63.

46. Stover EP, Siegel LC. Platelet-rich plasmapheresis in cardiac surgery: efficacy may yet be demonstrated. J Thorac Cardiovasc Surg. 1994;108:1148-9.

47. Wong CA, Franklin ML, Wade LD. Coagulation tests, blood loss, and transfusion requirements in platelet-rich plasmapheresed versus nonpheresed cardiac surgery patients. Anesth Analg. 1994;78:29-36.

48. Banbury MK, Brizzio ME, Rajeswaran J, Lytle BW, Blackstone EH. Transfusion increases the risk of postoperative infection after cardiovascular surgery. $J$ Am Coll Surg. 2006;202:131-8.

49. Casbard AC, Williamson LM, Murphy MF, Rege K, Johnson T. The role of prophylactic fresh frozen plasma in decreasing blood loss and correcting coagulopathy in cardiac surgery. A systematic review. Anaesthesia. 2004;59:550-8.

50. Koch C, Li L, Figueroa P, Mihaljevic T, Svensson L, Blackstone EH. Transfusion and pulmonary morbidity after cardiac surgery. Ann Thorac Surg. 2009;88 1410-8.

51. Hajjar LA, Vincent JL, Galas FR, Nakamura RE, Silva CM, Santos MH, et al Transfusion requirements after cardiac surgery: the TRACS randomized controlled trial. JAMA. 2010;304:1559-67.

52. Hebert PC, Yetisir E, Martin C, Blajchman MA, Wells G, Marshall J, et al. Is a low transfusion threshold safe in critically ill patients with cardiovascular diseases? Crit Care Med. 2001;29:227-34.

53. Rao SV, Jollis JG, Harrington RA, Granger CB, Newby LK, Armstrong PW, et al Relationship of blood transfusion and clinical outcomes in patients with acute coronary syndromes. JAMA. 2004;292:1555-62.

54. Vincent JL, Baron JF, Reinhart K, Gattinoni L, Thijs L, Webb A, et al. Anemia and blood transfusion in critically ill patients. JAMA. 2002;288:1499-507.

55. Carson JL, Duff A, Poses RM, Berlin JA, Spence RK, Trout R, et al. Effect of anaemia and cardiovascular disease on surgical mortality and morbidity. Lancet 1996;348:1055-60

56. Carson JL, Noveck H, Berlin JA, Gould SA. Mortality and morbidity in patients with very low postoperative $\mathrm{Hb}$ levels who decline blood transfusion. Transfusion. 2002;42:812-8

57. Westenbrink BD, Kleijn L, de Boer RA, Tijssen JG, Warnica WJ, Baillot R, et al Sustained postoperative anaemia is associated with an impaired outcome after coronary artery bypass graft surgery: insights from the IMAGINE trial. Heart. 2011;97:1590-6.

58. Bahrainwala ZS, Grega MA, Hogue CW, Baumgartner WA, Selnes OA McKhann GM, et al. Intraoperative hemoglobin levels and transfusion independently predict stroke after cardiac operations. Ann Thorac Surg. 2011;91:1113-8.

59. Ranucci M, La Rovere MT, Castelvecchio S, Maestri R, Menicanti L, Frigiola A et al. Postoperative anemia and exercise tolerance after cardiac operations in patients without transfusion: what hemoglobin level is acceptable? Ann Thorac Surg. 2011;92:25-31

60. Vivacqua A, Koch CG, Yousuf AM, Nowicki ER, Houghtaling PL, Blackstone EH, et al. Morbidity of bleeding after cardiac surgery: is it blood transfusion, reoperation for bleeding, or both? Ann Thorac Surg. 2011;91: 1780-90.

61. Green DR, Kroemer G. The pathophysiology of mitochondrial cell death. Science. 2004;305:626-9.

62. Loor G, Schumacker PT. Role of hypoxia-inducible factor in cell survival during myocardial ischemia-reperfusion. Cell Death Differ. 2008;15:686-90.

63. Weidemann A, Johnson RS. Biology of HIF-1alpha. Cell Death Differ. 2008;15 621-7. 
64. Tsui AK, Marsden PA, Mazer CD, Adamson SL, Henkelman RM, Ho JJ, et al. Priming of hypoxia-inducible factor by neuronal nitric oxide synthase is essential for adaptive responses to severe anemia. Proc Natl Acad Sci U S A. 2011;108: 17544-9.

65. Hare GM, Mazer CD, Mak W, Gorczynski RM, Hum KM, Kim SY, et al. Hemodilutional anemia is associated with increased cerebral neuronal nitric oxide synthase gene expression. J Appl Physiol. 2003;94:2058-67.

66. McLaren AT, Marsden PA, Mazer CD, Baker AJ, Stewart DJ, Tsui AK, et al. Increased expression of HIF-1alpha, nNOS, and VEGF in the cerebral cortex of anemic rats. Am J Physiol Regul Integr Comp Physiol. 2007;292: R403-14.

67. Koch CG, Li L, Duncan AI, Mihaljevic T, Loop FD, Starr NJ, et al. Transfusion in coronary artery bypass grafting is associated with reduced long-term survival. Ann Thorac Surg. 2006;81:1650-7.

68. Koch CG, Li L, Duncan AI, Mihaljevic T, Cosgrove DM, Loop FD, et al. Morbidity and mortality risk associated with red blood cell and blood-component transfusion in isolated coronary artery bypass grafting. Crit Care Med. 2006; 34:1608-16.

69. Koch CG, Khandwala F, Li L, Estafanous FG, Loop FD, Blackstone EH. Persistent effect of red cell transfusion on health-related quality of life after cardiac surgery. Ann Thorac Surg. 2006;82:13-20.

70. Surgenor SD, DeFoe GR, Fillinger MP, Likosky DS, Groom RC, Clark C, et al. Intraoperative red blood cell transfusion during coronary artery bypass graft surgery increases the risk of postoperative low-output heart failure. Circulation. 2006;114:I43-8.

71. Furnary AP, Wu Y, Hiratzka LF, Grunkemeier GL, Page US 3rd. Aprotinin does not increase the risk of renal failure in cardiac surgery patients. Circulation. 2007;116:I127-33.

72. Koch CG, Li L, Van Wagoner DR, Duncan AI, Gillinov AM, Blackstone EH. Red cell transfusion is associated with an increased risk for postoperative atrial fibrillation. Ann Thorac Surg. 2006;82:1747-56.

73. Chelemer SB, Prato BS, Cox PM Jr, O'Connor GT, Morton JR. Association of bacterial infection and red blood cell transfusion after coronary artery bypass surgery. Ann Thorac Surg. 2002;73:138-42.

74. Blumberg N, Heal JM. Immunomodulation by blood transfusion: an evolving scientific and clinical challenge. Am J Med. 1996;101:299-308.

75. Cherry T, Steciuk M, Reddy VV, Marques MB. Transfusion-related acute lung injury: past, present, and future. Am J Clin Pathol. 2008;129:287-97.
76. Kleinman S, Caulfield T, Chan P, Davenport R, McFarland J, McPhedran S, et al. Toward an understanding of transfusion-related acute lung injury: statement of a consensus panel. Transfusion. 2004;44:1774-89.

77. Popovsky MA. Transfusion-associated circulatory overload: the plot thickens. Transfusion. 2009;49:2-4.

78. Popovsky MA, Abel MD, Moore SB. Transfusion-related acute lung injury associated with passive transfer of antileukocyte antibodies. Am Rev Respir Dis. 1983;128:185-9.

79. Saidenberg E, Petraszko T, Semple E, Branch DR. Transfusion-related acute lung injury (TRALI): a Canadian blood services research and development symposium. Transfus Med Rev. 2010;24:305-24.

80. Gauvin F, Spinella PC, Lacroix J, Choker G, Ducruet T, Karam O, et al. Association between length of storage of transfused red blood cells and multiple organ dysfunction syndrome in pediatric intensive care patients. Transfusion. 2010;50:1902-13.

81. Koch CG, Li L, Sessler DI, Figueroa P, Hoeltge GA, Mihaljevic T, et al. Duration of red-cell storage and complications after cardiac surgery. N Engl J Med. 2008; 358:1229-39.

82. Sanders J, Patel S, Cooper J, Berryman J, Farrar D, Mythen M, et al. Red blood cell storage is associated with length of stay and renal complications after cardiac surgery. Transfusion. 2011;51:2286-94.

83. Bennett-Guerrero E, Veldman TH, Doctor A, Telen MJ, Ortel TL, Reid TS, et al. Evolution of adverse changes in stored RBCs. Proc Natl Acad Sci U S A. 2007; 104:17063-8.

84. Berezina TL, Zaets SB, Morgan C, Spillert CR, Kamiyama M, Spolarics Z, et al. Influence of storage on red blood cell rheological properties. J Surg Res. 2002; 102:6-12.

85. Kim-Shapiro DB, Lee J, Gladwin MT. Storage lesion: role of red blood cell breakdown. Transfusion. 2011;51:844-51.

86. Relevy H, Koshkaryev A, Manny N, Yedgar S, Barshtein G. Blood bankinginduced alteration of red blood cell flow properties. Transfusion. 2008;48:136-46.

87. Sweeney J, Kouttab N, Kurtis J. Stored red blood cell supernatant facilitates thrombin generation. Transfusion. 2009;49:1569-79.

88. Reynolds JD, Ahearn GS, Angelo M, Zhang J, Cobb F, Stamler JS. S-nitrosohemoglobin deficiency: a mechanism for loss of physiological activity in banked blood. Proc Natl Acad Sci U S A. 2007;104:17058-62.

89. Roback JD, Neuman RB, Quyyumi A, Sutliff R. Insufficient nitric oxide bioavailability: a hypothesis to explain adverse effects of red blood cell transfusion. Transfusion. 2011;51:859-66. 